\title{
Late life depression with cognitive impairment: Evaluation and treatment
}

\author{
Consuelo H Wilkins ${ }^{1,2}$ \\ Jose Mathews ${ }^{2}$ \\ Yvette I Sheline ${ }^{2}$ \\ 'Department of Medicine (Division \\ of Geriatrics and Nutritional \\ Science); ${ }^{2}$ Department of Psychiatry, \\ Washington University School of \\ Medicine, St. Louis, MO, USA
}

\begin{abstract}
Older adults with depression often present with signs and symptoms indicative of functional or cognitive impairment. These somatic symptoms make evaluating and treating depression in older adults more complex. Late life depression (LLD), depression in adults over the age of 65 , is more frequently associated with cognitive changes. Cognitive impairment in LLD may be a result of the depressive disorder or an underlying dementing condition. Memory complaints are also common in older adults with depression. There is a wide range of cognitive impairment in LLD including decreased central processing speed, executive dysfunction, and impaired short-term memory. The etiology of cognitive impairment in LLD may include cerebrovascular disease, a significant risk factor for LLD, which likely interrupts key pathways between frontal white matter and subcortical structures important in mood regulation. Because depressive symptoms often coexist with dementia, it is important to determine the temporal relationship between depressive symptoms and cognitive change. If depressive symptoms pre-date the cognitive impairment and cognitive symptoms are mild and temporary, LLD is the likely etiology of the cognitive impairment. If cognitive changes appear prior to depressive symptoms and persist after LLD is successfully treated, an underlying dementia is more likely. Clinicians should be exclude common conditions such as thyroid disease which can contribute to depressive symptoms and cognitive impairment prior to treating LLD. Both antidepressants and psychotherapy can be effective in treating LLD. Subsequent evaluations following treatment should also reassess cognition.
\end{abstract}

Keywords: late life depression, cognitive impairment, diagnosis, treatment, cognition

\section{Introduction}

Depression in older adults is a serious illness and may lead to impaired physical function, increased mortality, and unwarranted use of health care resources. Late life depression (LLD), depression occurring in patients over age 65, remains under-diagnosed and under-treated. The prevalence of LLD varies depending on the population studied, affecting up to $9 \%$ of community dwelling elderly but $25 \%$ of institutionalized elderly and those recently hospitalized. ${ }^{1,2}$ Compared to adults with depression earlier in life (early onset depression), patients with late-onset depression (first episode after age 65) are less likely to have a family history of depression and are likely to have significant comorbidities, especially cardiovascular diseases. Consequently, environmental factors and lifestyle factors may be associated with the development of LLD.

Patients with LLD often present with cognitive complaints or cognitive deficits. These cognitive changes may occur as a consequence of depression or may indicate a coexisting condition such as Alzheimer's disease or Parkinson's disease. Establishing whether depression is the primary cause of cognitive change or whether a concomitant dementing illness exists is important in the management of the disease. Since more than $75 \%$ of care for LLD is provided by non-psychiatrists, it is imperative that primary care providers are able to diagnosis LLD and distinguish it from other diseases which can present with similar symptoms. 


\section{Pathophysiology}

LLD is thought to be pathophysiologically different from depression in young adults as it is often associated with comorbid illnesses. Risk factors for LLD include stressors such as living alone, chronic pain, and comorbid illnesses such as cardiovascular disease. See Table 1 for additional risk factors.

Over the last two decades, studies have identified important biological and cognitive correlates of depression in late life. Among these are associations with morphologic abnormalities in key brain structures and neuropsychological abnormalities in executive function and memory. ${ }^{3-5}$ Several studies have found a strong association between cerebrovascular risk factors and LLD ${ }^{6,7}$ In some individuals, vascular disease may contribute to the development of a late life depression syndrome by interrupting the connections between frontal white matter pathways and subcortical structures (such as basal ganglia) involved in mood. ${ }^{8-10}$

The term vascular depression has emerged from imaging findings of white matter hyperintensities associated with LLD. Studies have found that patients with LLD and structural magnetic resonance imaging (MRI) evidence of cerebrovascular disease have greater neuropsychological impairment on testing. ${ }^{11,12} \mathrm{We}$ found a wide range of disruption of cognitive functioning in LLD, in particular, processing speed was a core cognitive

Table I Risk factors for late life depression ${ }^{28,29}$

Gender (Women are more likely than men)
Social isolation
Alcohol use
Medications
- Chronic benzodiazepine use
- Narcotics
- Antihypertensives (beta blockers)
- Interferon alpha
Death of spouse or close loved-one
Severe and chronic pain
Medical illnesses
- Cancer
- Hypothyroidism
- Stroke
- Dementing Illnesses- (Alzheimer's disease, Parkinson's disease)
- Myocardial Infarction
- Coronary artery bypass surgery
-
-

deficit. ${ }^{13}$ It is hypothesized that cerebrovascular ischemia disrupts brain circuitry and results in depression as well as neuropsychological impairment. Clinical factors that might be linked to worse neuropsychological performance in LLD, include depression severity, comorbid anxiety, vegetative symptoms, number of prior episodes, age and late age of depression onset. ${ }^{14,15}$ Cognitive impairment in LLD has also been shown to be greater in late-onset depression. ${ }^{16}$

\section{Diagnosis}

Although the diagnostic criteria for LLD are the same as depression in younger adults, patients with LLD often present with more somatic symptoms. Making a diagnosis of LLD can be difficult for many reasons including more subtle presentations in older adults, coexisting medical illnesses, and reluctance to self-report symptoms. In addition to the obvious signs of depression, patients with LLD may have nonspecific symptoms which may be confused with physical illness such as psychomotor slowing, fatigue, and increased pain.

Additionally, many clinicians use the term 'depression' not only in reference to a major depressive episode (MDE), but also to describe a symptom or other nonspecific syndrome. The diagnostic criteria for depression/MDE and special considerations in older adults are presented in Table 2.

Table 2 DSM-IV diagnostic criteria for episode of major depression and special considerations in late life depression

Five or more of the following 9 symptoms present nearly every day for at least 2 weeks (at least one symptom being depressed mood or diminished interest or pleasure):

I. Depressed mood

2. Markedly diminished interest or pleasure in almost all activities

3. Fatigue or loss of energy

4. Feelings of worthlessness or excessive or inappropriate guilt

5. Clinically significant weight loss or weight gain or decrease in appetite

6. Insomnia or hypersomnia

7. Observable psychomotor agitation or retardation

8. Diminished ability to think or concentrate, or indecisiveness

9. Recurrent thoughts of death or suicidal ideation

Special considerations for older adults with depressive symptoms

- Coexisting memory complaints are common

- Many older adults believe depression is normal with aging

- Psychosocial risk factors for depression are common

- Symptoms from chronic medical illnesses (fatigue, weight loss) may overlap with depressive symptoms

- Older men have highest rates of suicide 
Diagnosing LLD can be especially challenging in those with cognitive impairment. Whether cognitive changes in the setting of LLD signals a coexisting illness or is simply an effect of the depression is a complex question. Some older adults present with cognitive complaints yet meet criteria for depression; similarly, older adults may report depressed mood but are actually demented. Although pseudodementia can be caused by LLD, pseudodementia is relatively uncommon and depression commonly coexists with dementing illnesses including $40 \%$ of Parkinson's disease, $20 \%-30 \%$ of Alzheimer's disease, and 30\%-60\% of stroke patients.

The evaluation of depressive symptoms and cognitive changes must include a complete history and physical with a detailed neurological exam to determine whether focal deficits or parkinsonism are present. Laboratory tests for thyroid disease, B12 deficiency, anemia, and renal impairment should be performed to exclude an underlying medical illness. A brief interview with the patient's spouse, adult child, other relative or friend is extremely helpful in determining whether the patient's symptoms are most likely depression or an underlying dementia. ${ }^{17}$ If depressive symptoms began prior to or concurrent with cognitive changes, depression may be more likely. If cognitive changes are more consistent and preceded the depressive symptoms, more consideration of a dementing illness is warranted.

Following the history and physical, depressive symptoms should be assessed using a screening tool. Several screening tools have been successfully used to identify LLD. These screens can help detect depressive symptoms but they should not be used independently to diagnose LLD. Patients who screen positive should be further interviewed to determine whether diagnostic criteria for depression are met.

Although there are numerous screening instruments, it is important to identify screening tools that have been validated and are easy to administer and interpret. The Geriatric Depression Scale (GDS), Patient Health Questionnaire-9 (PHQ-9), and the Center for Epidemiologic Studies Depression Scale (CES-D) are all useful for identifying depressive symptoms in the elderly.

The GDS has been studied in multiple settings and was designed specifically for older adults. ${ }^{18}$ The fifteen-item version has demonstrated good operating characteristics across the full spectrum of elderly populations. Five or more depressive symptoms suggest the diagnosis of depression. The instrument can be self administered or given by the clinician/staff.
The PHQ-9 was developed specifically for use in primary care settings and has demonstrated validity and reliability. ${ }^{19}$ It encompasses all nine DSM-IV criteria for major depression and has been shown to be a reliable measure of depression treatment outcomes in a large study of older adults. The full PHQ-9 is shown in Figure 1. The tool can also be used to assess response to treatment in individual patient care.

The CES-D is commonly used in primary care settings for the assessment of depressive symptoms. ${ }^{20}$ Although it has been used in older adults, the instrument was developed for research not for the clinical setting so individual scores must be interpreted with caution.

Assessment of cognitive performance using a tool such as the Mini-Mental State Exam, the Short Blessed Test, or other cognitive screening tool should be performed. While these screening tools alone should not be used to determine whether the patient is cognitively impaired, they may be useful in following cognitive performance during and after treatment of depression. If cognitive impairment persists after depressive symptoms improve, additional evaluations to exclude underlying or coexisting dementia should be pursued. This evaluation should include brain imaging to exclude stroke, tumor, and normal pressure hydrocephalus.

\section{Addressing psychosocial risk factors}

Psychosocial risk factors for LLD are common and many older adults with depression often have more than one risk factor. Common psychosocial factors in LLD include loss of function or physical disability, bereavement, caregiver stress, lack of social support, and change in societal roles (ie, retirement). ${ }^{21}$ It is important to identify these risk factors and determine their effect on LLD. Unfortunately, there are no existing tools that accurately predict risk of LLD based on psychosocial risk factors. The clinician should ask patients with depression whether recent life events are contributing to depressive symptoms as patients with significant psychosocial risk factors may benefit more from psychotherapy.

\section{Treatment}

After the careful diagnosis of LLD, the initial treatment of choice in the primary care setting is the use of antidepressant medications. There is also good evidence for the efficacy of psychotherapy as a treatment option;22 however, this requires a specialist referral. The overarching principal, as in other areas of geriatric medicine, is to use a low starting dose and to slowly increase the dose as necessary. It is usual to start treatment with one half of the younger adult starting dose and to make subsequent 
Name Date

Over the last 2 weeks, how often have you been bothered by any of the following problems?

$\begin{array}{llll}\text { Not at } & \text { Several } & \text { More } & \text { Nearly } \\ \text { all } & \text { days } & \text { than half } & \text { every day } \\ & & \text { the days }\end{array}$

1. Little interest or pleasure in doing things

2. Feeling down, depressed, or hopeless

0

2

3

0

2

3. Trouble falling or staying asleep, or sleeping too much

4. Feeling tired or having little energy

0

5. Poor appetite or overeating

6. Feeling bad about yourself-or that you are a

failure or have let yourself or your family down

7. Trouble concentrating on things, such as reading the newspaper or watching television

8. Moving or speaking so slowly that other people could have noticed? Or the opposite—being so fidgety or restless that you have been moving around a lot

more than usual

9. Thoughts that you would be better off dead or of hurting yourself in some way

$\begin{array}{llll}0 & 1 & 2 & 3\end{array}$

(For office coding: Total Score

If you checked off any problems, how difficult have these problems made it for you to do your work, take care of things at home, or get along with other people?

Not difficult at all Somewhat difficult Very difficult Extremely difficult

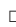

口 口

\section{Scoring-add all checked boxes on PHQ-9. \\ Total Score Depression Severity \\ 0-4 None \\ 5-9 Mild depression \\ 10-14 Moderate depression \\ 15-19 Moderately severe depression \\ 20-27 Severe depression}

From the Primary Care Evaluation of Mental Disorders Patient Health Questionnaire (PRIME-MD

PHQ). PHQ-9 @ 1999 Pfizer Inc. All rights reserved. Reproduced with permission from Pfizer Inc.

Figure I PHQ-9 for the assessment of depression. 
titrations in small dose intervals. Selective serotonin reuptake inhibitors (SSRIs) are the most commonly used first line treatment for depression including LLD as they have relatively low toxicity and high tolerability. ${ }^{23,24}$ Of the SSRIs, citalopram was used in a large NIH funded multi-center trial, the STAR*D trial, for the treatment of depression that included patients with late life depression. ${ }^{24}$ Citalopram was chosen for its once a day dosing, lack of discontinuation side-effects and low potential for drug-drug interaction, all attractive characteristics in LLD. Other choices include escitalopram with a similar profile as citalopram and sertraline (favorable profile at low dose) amongst other SSRIs (Table 3). The newer generation of antidepressants has a more diverse mechanism of action than the selective serotonin inhibition. These can be used as first line treatment, although the data supporting its use in LLD is limited (Table 3). The older antidepressant medications include the tricyclic antidepressants such as desipramine and the monoamine oxidase inhibitors such as selegiline have limited use in the elderly. These medications have significant side effect liability and are best prescribed and monitored by a psychiatrist.
Inadequate trial duration and suboptimal dosing are the two most common reasons for low treatment response. Adequate trial duration is at least 8 weeks of treatment and the dose should be carefully increased to the upper dosage range, as tolerated, if patient shows no response. Also, SSRI and other antidepressant medications take at least two weeks before any improvement is noticed, with optimal reduction in symptoms taking as long as $8-12$ weeks. It is therefore prudent to wait for a minimum of two weeks before dose increases. It is best to discuss this lag period with the patient and their caregivers in the process of obtaining informed consent; also, the concern that the SSRI group of medications may cause increased suicidal ideations should be made explicit. All antidepressants can cause GI symptoms during the initial treatment period and are usually self limiting; further reduction of dosage or a switch to another agent can remedy this. Sexual dysfunction may be another of the side effects that should be discussed. Table 4 includes a list of common side effects of some antidepressants.

Along with the medication, it is important to assess the adequacy of social support, any impediment to medication

Table 3 Select antidepressants

\begin{tabular}{|c|c|c|c|c|}
\hline Antidepressant & Initial dose & Dosage range & Pharmacokinetics & Comments \\
\hline \multicolumn{5}{|l|}{ SSRI: } \\
\hline $\begin{array}{l}\text { I. Citalopram } \\
\text { (Celexa) }\end{array}$ & $10 \mathrm{mg}$ & $20-40 \mathrm{mg}$ & $\begin{array}{l}\text { Weak inhibitor of CYP450 } \\
\text { 2D6 }\end{array}$ & $\begin{array}{l}\text { Well tolerated.Tramadol may } \\
\text { increase risk of seizure }\end{array}$ \\
\hline $\begin{array}{l}\text { 2. Escitalopram } \\
\text { (Lexapro) }\end{array}$ & $5 \mathrm{mg}$ & $10-20 \mathrm{mg}$ & $\begin{array}{l}\text { No significant action on } \\
\text { CYP450 }\end{array}$ & $\begin{array}{l}\text { Well tolerated. Caution if history of } \\
\text { seizure }\end{array}$ \\
\hline $\begin{array}{l}\text { 3. Sertraline } \\
\text { (Zoloft) }\end{array}$ & $25 \mathrm{mg}$ & 50-200 mg & $\begin{array}{l}\text { Inhibits CYP450 2D6 and } \\
\text { 3A4 (weakly at low doses) }\end{array}$ & $\begin{array}{l}\text { Caution with use of HMG CoA } \\
\text { reductase inhibitors. Tramadol, } \\
\text { Alprazolam, Thioridazine }\end{array}$ \\
\hline $\begin{array}{l}\text { 4. Fluoxetine } \\
\text { (Prozac) }\end{array}$ & $5 \mathrm{mg}$ & $10-40 \mathrm{mg}$ & $\begin{array}{l}\text { Inhibits CYP450 2D6 and } \\
3 A 4\end{array}$ & $\begin{array}{l}\text { Long half life ( } 2 \text { weeks). Other } \\
\text { cautions as for sertraline }\end{array}$ \\
\hline \multicolumn{5}{|l|}{ 5. Paroxetine } \\
\hline (Paxil) & $10 \mathrm{mg}$ & $10-40 \mathrm{mg}$ & Inhibits CYP450 2D6 & $\begin{array}{l}\text { Caution with thioridazine, drugs } \\
\text { with anticholinergic properties and } \\
\text { theophylline }\end{array}$ \\
\hline \multicolumn{5}{|l|}{ Others: } \\
\hline $\begin{array}{l}\text { 6. Bupropion SR } \\
\text { (Wellbutrin) }\end{array}$ & $100 \mathrm{mg}$ & $100-400 \mathrm{mg}$ & Inhibits CYP450 2D6 & $\begin{array}{l}\text { Increases risk for seizure. Caution } \\
\text { with levodopa and amantadine }\end{array}$ \\
\hline $\begin{array}{l}\text { 7.Venlafaxine XR } \\
\text { (Effexor XR) }\end{array}$ & $37.5 \mathrm{mg}$ & $75-225 \mathrm{mg}$ & $\begin{array}{l}\text { No significant action on } \\
\text { CYP450 }\end{array}$ & $\begin{array}{l}\text { Increased BP that is dose dependent. } \\
\text { SIADH, Hyponatremia. Do NOT use } \\
\text { in uncontrolled glaucoma }\end{array}$ \\
\hline $\begin{array}{l}\text { 8. Duloxetine } \\
\text { (Cymbalta) }\end{array}$ & $20 \mathrm{mg}$ & $40-60 \mathrm{mg}$ & $\begin{array}{l}\text { Inhibits CYP450 2D6 and } \\
\text { IA2 }\end{array}$ & $\begin{array}{l}\text { Monitor BP as it may increase. Do } \\
\text { NOT use in uncontrolled glaucoma } \\
\text { or with thioridazine }\end{array}$ \\
\hline $\begin{array}{l}\text { 9. Mirtazapine } \\
\text { (Remeron) }\end{array}$ & $7.5 \mathrm{mg}$ & $15-45 \mathrm{mg}$ & $\begin{array}{l}\text { No significant action on } \\
\text { CYP450 }\end{array}$ & $\begin{array}{l}\text { May increase cholesterol, cause } \\
\text { photosensitivity and rarely lower } \\
\text { WBC count. }\end{array}$ \\
\hline
\end{tabular}


Table 4 Common side effects of SSRIs

\section{Nausea}

Vomiting

Diarrhea

Anorexia (early in the treatment)

Sedation

Sexual dysfunction

Insomnia

Hyponatremia

compliance and other illnesses that may adversely impact depression. Interventions to improve social support may include educating the family about depression and the need for more close monitoring and encouragement to attend spiritual activities. Compliance with medication may be enhanced with the use of a pillbox and involvement of a caregiver. Optimal treatment of patients' co-morbid medical illnesses will contribute to patients' improved sense of well-being and mental health.

\section{When to refer}

\section{Severity}

The severity of depression will determine the aggressiveness of the treatment approach. Any suicidal ideation, weight loss due to decreased food intake, low fluid intake, and psychomotor retardation alongside intense low mood will require a more aggressive management strategy. Such severe depression will warrant an aggressive treatment strategy and may require the use of electroconvulsive therapy (ECT), combination antidepressant therapy, use of tricyclics or monoamine oxidase inhibitors, all requiring prompt referral to a psychiatrist. The psychiatrist may treat this patient alongside the primary care physician or serve as a consultant who does crisis intervention. The primary care provider may continue managing the patient's depression once the severity of depression has lessened and patient has achieved response or preferably, remission.

\section{Psychotherapy}

The efficacy of psychotherapy is well supported by literature for treatment of mild to moderate depression. ${ }^{22}$ Patients who wish to avoid or delay antidepressants and those with significant psychosocial risk factors may be good candidates for psychotherapy. Both cognitive behavioral therapy (CBT) and interpersonal psychotherapy (IPT) are effective in older adults with depression including those with cognitive impairment. CBT focuses on modifying everyday thoughts and behaviors by positively influencing emotions. Distorted thinking is recognized and replaced with more realistic substitute ideas. In IPT, education about depression is provided and interpersonal events that could be associated with depressive symptoms are explored. Possible solutions are also pursued. A licensed mental health therapist will provide appropriate psychotherapy.

\section{Failure of first-line antidepressant medication}

If patient does not respond to the first-line antidepressant medication treatment, it may be best to obtain a psychiatrist intervention. The treatment options at this stage include use of augmentation with another antidepressant/psychotherapy or switching to another agent. This becomes a complex issue and a specialist will be able to offer a larger spectrum of treatment options. Failure of antidepressant therapy may also indicate an underlying cognitive impairment.

\section{Recurrent or relapsing depression}

Longitudinal studies indicate that a significant number of patients are at a high risk of relapse even after successful treatment. ${ }^{25}$ Biological and social factors both affect an elderly individual's long-term course of depression, both in the acute phase and longer term. Although there is significant individual variability in disease course in patients with LLD, a greater number of previous depressive episodes increases the risk of future relapse and decreases time to relapse. ${ }^{26,27}$

Depressed elderly individuals who do not respond to first-line antidepressant therapy, who exhibit greater residual depressive symptoms, or who require a longer time to respond to treatment are at higher risk of relapse. Discontinuation of maintenance antidepressant therapy in elderly individuals also carries a high risk. Accordingly, a referral to a psychiatrist may improve treatment outcomes.

\section{Disclosure}

The authors report no conflicts of interest in this work. This work was supported in part by the Barnes-Jewish Hospital Foundation (22-3057-41583, PI-Wilkins) and the National Institutes of Health (AG026768, PI-Wilkins).

\section{References}

1. Lebowitz BD, Pearson JL, Schneider LS, et al. Diagnosis and treatment of depression in late life: consensus statement update. JAMA. 1997;278:1186-90.

2. Teresi J, Abrams R, Holmes D, et al. Prevalence of depression and depression recognition in nursing homes. Soc Psychiatry Psychiatr Epidemiol. 2001;36:613-20. 
3. Sheline YI. 3D MRI studies of neuroanatomic changes in unipolar major depression: The role of stress and medical comorbidity. Biol Psychiatry. 2000;48:791-800.

4. Sheline YI, Wang PW, Gado MH, et al. Hippocampal atrophy in recurrent major depression. Proc Natl Acad Sci US A. 1996;93:3908-13.

5. Taylor WD, Steffens DC, MacFall JR, et al. White matter hyperintensity progression and late-life depression outcomes. Arch Gen Psychiatry. 2003;60:1090-6.

6. Figiel GS, Krishnan KRR, Doraiswamy PM, et al. Subcortical hyperintensities on brain magnetic resonance imaging: a comparison between late age onset and early onset elderly depressed subjects. Neurobiol Aging. 1991;12:245-7.

7. Lyness JM, Caine ED, Cox C, et al. Cerebrovascular risk factors and later-life major depression: Testing a small-vessel brain disease model. Am J Geriatr Psychiatry. 1998;6:5-13.

8. Kramer-Ginsberg E, Greenwald BS, Krishnan KR, et al. Neuropsychological functioning and MRI signal hyperintensities in geriatric depression. Am J Psychiatry. 1999;156:438-44.

9. Heiden A, Kettenbach J, Fischer P, et al. White matter hyperintensities and chronicity of depression. J Psychiatr Res. 2005;39:285-93.

10. O'Brien JT, Firbank MJ, Krishnan MS, et al; on behalf of the LADIS Group. White matter hyperintensities rather than lacunar infarcts are associated with depressive symptoms in older people: The LADIS study. Am J Geriatr Psychiatry. 2006;14:834-41.

11. Bennett DA, Wilson RS, Schneider JA, et al. Cerebral infarctions and the relationship of depression symptoms to level of cognitive functioning in older persons. Am J Geriatr Psychiatry. 2004;12:211-9.

12. Trichard C, Martinot JL, Alagille M. Time course of prefrontal lobe dysfunction in severely depressed in patients: a longitudinal neuropsychological study. Psychol Med. 1995;25:79-85.

13. Sheline YI, Barch DM, Garcia K, et al. Cognitive function in late life depression: relationships to depression severity, cerebrovascular risk factors and processing speed. Biol Psychiatry. 2006;60:58-65.

14. Lesser IM, Boone KB, Mehringer CM, et al. Cognition and white matter hyperintensities in older depressed patients. Am J Psychiatry. 1996;153:1280-7.

15. Lichtenberg PA, Ross T, Millis SR, et al. The relationship between depression and cognition in older adults: a cross-validation study. J Gerontol. 1995;50B:P25-P32.

16. Butters MA, Whyte EM, Nebes RD, et al. The nature and determinants of neuropsychological functioning in late-life depression. Arch Gen Psychiatry. 2004;61:587-95.
17. Carr DB, Gray S, Baty J, et al. The value of informant versus individual's complaints of memory impairment in early dementia. Neurology. 2000;55:1724-7.

18. Sheikh JI, Yesavage JA. Geriatric Depression Scale (GDS): Recent evidence and development of a shorter version. Clinical Gerontology: A Guide to Assessment and Intervention, New York: The Haworth Press, 1986. p 165-73.

19. Spitzer R, Kroenke K, Williams J. Validation and utility of a selfreport version of PRIME-MD: the PHQ Primary Care Study. JAMA. 1999;282:1737-44.

20. Radloff LS. The CES-D scale: A self-report depression scale for research in the general population. Appl Psychol Measure. 1977;1:385-401.

21. Bruce ML. Psychosocial risk factors for depressive disorders in late life. Biol Psychiatry. 2002;52:175-84.

22. Cuijpers P, van Straten A, Smit F. Psychological treatment of late-life depression: a meta-analysis of randomized controlled trials. Int J Geriatr Psychiatry. 2006;21:1139-49.

23. Mulsant BH, Alexopoulos GS, Reynolds CF 3rd, et al; PROSPECT Study Group. Pharmacological treatment of depression in older primary care patients: the PROSPECT algorithm. Int J Geriatr Psychiatry. 2001;16:585-92.

24. Rush AJ, Fava M, Wisniewski SR, et al; STAR*D Investigators Group. Sequenced treatment alternatives to relieve depression (STAR*D) rationale and design. Control Clin Trials. 2004;25:119-42.

25. Beekman AT, Geerlings SW, Deeg DJ, et al. The natural history of late-life depression: a 6-year prospective study in the community. Arch Gen Psychiatry. 2002;59:605-11.

26. Kessing LV, Andersen PK, Mortensen PB, et al. Recurrence in affective disorder. I. Case register study. Br J Psychiatry. 1998;172:23-8.

27. Kessing LV, Hansen MG, Andersen PK. Course of illness in depressive and bipolar disorders. Naturalistic study, 1994-1999. Br J Psychiatry. 2004; 185:372-7.

28. Schoevers RA, Smit F, Deeg DJH, et al. Prevention of late-life depression in primary care: do we know where to begin? Am J Psychiatry. 2006;163:1611-21.

29. Koenig HG, Blazer DG. Depression, anxiety, and other mood disorders. In: Cassel CK, Leipzig RM, Cohen HJ, et al. (eds). Geriatric medicine: an evidence-based approach. 4th edition. New York: Springer-Verlag, 2003. p. 1163-83. 
